\title{
Involvement of calcium regulating ion channels in contractility of human isolated urinary bladder
}

\author{
Jan Luptak ${ }^{1}$, Michaela Kocmalova ${ }^{2,3}$, Sona Franova ${ }^{2,3}$, Juraj Sutovsky ${ }^{4}$, Marian Grendar ${ }^{3}$, Jan \\ Svihra ${ }^{1}$, Jan Kliment Sr${ }^{1}$, Robert Dusenka ${ }^{1}$ and Martina Sutovska ${ }^{2,3}$ \\ ${ }^{1}$ Urology Clinic, Jessenius Faculty of Medicine, Martin University Hospital, Comenius University, Martin, Slovakia \\ ${ }^{2}$ Department of Pharmacology, Martin's Biomedical Center (BioMed), Jessenius Faculty of Medicine, Comenius University, \\ Martin, Slovakia \\ ${ }^{3}$ Martin's Biomedical Center (BioMed), Jessenius Faculty of Medicine, Comenius University, Martin, Slovakia \\ ${ }^{4}$ Neurosurgery Clinic, Jessenius Faculty of Medicine, Martin University Hospital, Comenius University, Martin, Slovakia
}

\begin{abstract}
This study specified the role of several key calcium-operating ion channels in contraction/ relaxation of human detrusor muscle as possible target for overactive bladder (OAB) treatment. Detrusor samples, obtained from 18 males (average age $61.5 \pm 5.9$ years), were investigated by organ tissue bath method with following agents: diltiazem for L-type voltage-gated calcium channels; 3-fluropyridine-4-carboxylic acid (FPCA) for Orai-STIM channels; SKF 96365-hydrochloride for transient receptor potential (TRP) channels, T-type channels and Orai-STIM channels; 2- aminoethoxydiphenyl borate (2-APB) for inositol-triphosphate receptors ( $\mathrm{IP}_{3} \mathrm{Rs}$ ) and Orai-STIM channels. Oxybutynin and mirabegron were tested under the same conditions as controls. Mirabegron, 2-APB and FPCA exhibited the best suppressive effect on carbachol-induced detrusor contractility. As expressed by area under the contractile curve (AUCC), 2-APB, FPCA and mirabegron have similar AUCC: 1.79, 1.73, 1.73. The highest AUCC was 3.64 for diltiazem+SKF, followed by 3.21 for diltiazem, 3.16 for SKF and 2.94 for oxybutynin. The lowest median amplitude and contraction variability is for 2-APB followed by mirabegron and FPCA. There were significant differences between: 2-APB/FPCA vs.: ditiazem, diltiazem+SKF and SKF. Summary of results suggested the principal role of $\mathrm{IP}_{3} \mathrm{Rs}$, Orai-STIM coupling and large-conductance calcium-activated potassium channels in detrusor contraction and pointed on Orai-STIM channels as possible targets for OAB pharmacotherapy.
\end{abstract}

Key words: Overactive bladder - Smooth muscle - Calcium ion channels - Orai-STIM pathway - Organ tissue bath

\section{Introduction}

The relaxation of detrusor is mediated by tonic release of norepinephrine, which activates beta adrenergic receptors ( $\beta_{3}$-ARs in human detrusor) and by intrinsic urinary bladder smooth muscle (UBSM) properties. The contraction is achieved by acetylcholine that activates UBSM

Correspondence to: Martina Sutovska, Department of Pharmacology, BioMed (Martin's Biomedical Center), Jessenius Faculty of Medicine, Comenius University, Malá Hora, 11161 4D, 03601 Martin, Slovakia

E-mail: sutovska@jfmed.uniba.sk muscarinic receptors (mainly $\mathrm{M}_{3}$ ). Disturbances in these functions may result in lower urinary tract symptoms, such as urgency, frequency, and urge incontinence, the components of the overactive bladder syndrome (OAB) (Andersson 2015).

At the cellular level, delicate balance of mechanisms maintaining cytoplasmic calcium $\left(\mathrm{Ca}^{2+}\right)$ levels is critical to normal detrusor function. Increases of intracellular $\mathrm{Ca}^{2+}$ resulting in contraction occur primarily due to extracellular $\mathrm{Ca}^{2+}$ entry through plasmalemmal ion channels or release of $\mathrm{Ca}^{2+}$ from the endoplasmic/sarcoplasmic reticulum (ER/ SR) (Fig. 1). The propagation of UBSM action potential result from $\mathrm{Ca}^{2+}$ entry through L-type voltage-gated ion channels 


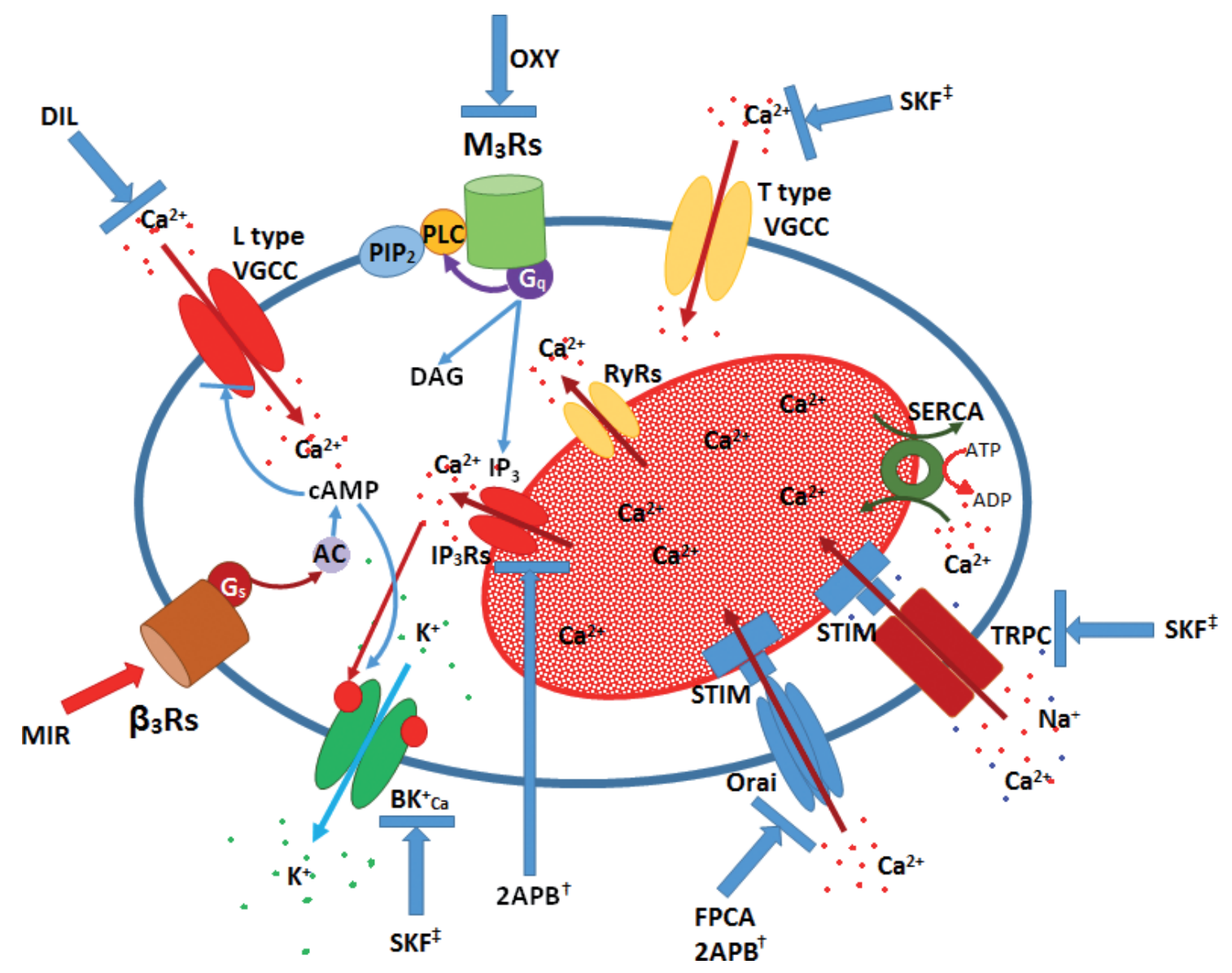

Figure 1. Proposed regulation of $\mathrm{Ca}^{2+}$ homeostasis in urinary bladder smooth muscle (UBSM) cells. Muscarinic agonists bind to $\mathrm{M}_{3}$ receptors, triggering the formation of diacylglycerol (DAG) and inositol 1,4,5-trisphosphate $\left(\mathrm{IP}_{3}\right) . \mathrm{IP}_{3}$ activates $\mathrm{IP}_{3}$ receptor $\left(\mathrm{IP} \mathrm{P}_{3} \mathrm{R}\right)$ mediated $\mathrm{Ca}^{2+}$ release. Subsequent depletion of $\mathrm{Ca}^{2+}$ from the sarcoplasmic reticulum (SR) in turn activates store-operated channels (transient receptor potential (TRPC) channels and Orai-STIM channels)-mediated $\mathrm{Ca}^{2+}$ entry. $\beta_{3}$-AR agonists stimulate adenylyl cyclase to increase cAMP. In turn, cAMP activates PKA to mediate their biological effects, mainly inhibition of intracellular $\mathrm{Ca}^{2+}$ via activation of large conductance $\mathrm{Ca}^{2+}$ activated potassium channels $\left(\mathrm{BK}^{+} \mathrm{Ca}\right) . \mathrm{BK}^{+} \mathrm{Ca}$ channels are also stimulated by $\mathrm{Ca}^{2+}$-released through ryanodine receptors (RyRs). L-type of voltage gated ion calcium channels (VGCC) is mediated depolarization and it is believed to be responsible for calcium-induced currents from SR. T-type VGCC contribute to the generation of spontaneous electrical activity. Arrows show sites of tested modulators action: $\rightarrow \mid$ (blue), inhibitory and $\rightarrow$ (red), stimulatory effects. MIR, mirabegron; OXY, oxybutynin; 2APB, 2 - aminoethoxydiphenyl borate; FPCA, 3-fluropyridine-4-carboxylic acid; SKF, SKF 96365 hydrochloride; DIL, diltiazem. $\dagger 2 \mathrm{APB}$ at $\mathrm{c}=$ $1-10 \mu \mathrm{M}$ inhibits $\mathrm{IP}_{3} \mathrm{Rs}$; while it’s $\mathrm{c}=0.1-1 \mathrm{mM}$ blocks Orai -STIM. $\ddagger$ SKF at $\mathrm{c}=1-10 \mu \mathrm{M}$ inhibits T-type VGCC; from $\mathrm{c}=10 \mu \mathrm{M}$ blocks also TRPC, $\mathrm{K}^{+} \mathrm{ATP}$ and $\mathrm{BK}^{+} \mathrm{Ca}$ channels, and prevents STIM1-Orail coupling.

(VGCC) (Parajuli et al. 2016). The recent studies documented that $\mathrm{M}_{3}$ receptor-mediated detrusor contractions also require $\mathrm{Ca}^{2+}$ influx via L-type VGCC (Hedge 2006). $\mathrm{Ca}^{2+}$ influx through T-and L-type VGCC also determined the contractile status of UBSM, and, furthermore, T-type channel activity is important to maintain membrane potentials near the resting level (Sui et al. 2007). Nonselective cation channels such as transient receptor potential (TRP) channels significantly contribute on extracellular $\mathrm{Ca}^{2+}$ entry pathways in UBSM cells.
Although a number of intracellular organelles take up and release $\mathrm{Ca}^{2+}, \mathrm{ER} / \mathrm{SR}$ represents the largest pool of releasable $\mathrm{Ca}^{2+}$ in smooth muscle cells. In response to a variety of stimuli $\mathrm{Ca}^{2+}$-release channels in the SR, namely ryanodine receptors (RyRs) and inositol-trisphosphate receptors $\left(\mathrm{IP}_{3} \mathrm{Rs}\right)$, mediate efflux of $\mathrm{Ca}^{2+}$ from the SR into the cytoplasm of the cell (Hill-Eubanks et al. 2011).

UBSM hyperactivity, such as OAB, can be successfully treated with muscarinic receptor antagonists (e.g. oxybutynin, tolterodine, fesoterodine or trospium) and 
beta adrenergic receptor agonists (e.g. mirabegron). In addition to $\mathrm{Ca}^{2+}$ homeostasis, administration of both pharmacological groups influence transport of $\mathrm{Ca}^{2+}$ through plasma membrane or its release from SR. Mirabegron, $\beta_{3}$-ARs agonist, represents a novel treatment strategy for overactive bladder. The canonical signaling pathway of $\beta_{3}$-ARs is stimulation of adenylyl cyclase to form cyclic adenosine $3^{\prime}, 5^{\prime}$-monophosphate (cAMP), resulting in activation of protein kinase A (PKA) which can suppress calcium-calmodulin-dependent myosin/actin interaction upon phosphorylation of myosin light chain kinase (Cernecka et al. 2015). Despite this, compelling evidence suggests that $\beta_{3}$-ARs can also stimulate large-conductance calcium-activated potassium $\left(\mathrm{BK}^{+} \mathrm{Ca}\right)$ channels, e.g. in rodent (Hristov et al. 2008) and human bladder (Afeli et al. 2013) and this way indirectly inhibit L-type VGCC. On the other hand, the antimuscarinic agents inhibit processes triggered by activation of $\mathrm{M}_{3}$ receptors, especially emptying of $\mathrm{Ca}^{2+}$ from SR through the activation of $\mathrm{IP}_{3} \mathrm{Rs}$. There is also the strong evidence that $\mathrm{BK}^{+} \mathrm{Ca}$ channel activity is inhibited upon $M_{3}$ receptors activation and this mechanism contributes on suppressed UBSM contraction on administered antimuscarinics (Parajuli et al. 2016). Unlike $\mathrm{IP}_{3} \mathrm{Rs}$, spontaneous RyRs-mediated $\mathrm{Ca}^{2+}$ release plays a negative role in UBSM activity by the activation of $\mathrm{BK}^{+} \mathrm{Ca}$ channels (Herrera and Nelson 2002).

However, recent possibilities of $\mathrm{OAB}$ pharmacotherapy have still several limitations. The patients may have a suboptimal response or antimuscarinic therapy is limited by associated compelling diagnosis or adverse events, e.g. dry mouth as the most common and altered cardiovascular and central nervous functions as the most severe adverse effects. According clinical trials, mirabegron was effective and well tolerated in patients with OAB (Khullar et al. 2013). However, preclinical safety data showed that mirabegron caused hepatotoxic, cardiovascular and CNS toxic adverse findings and thus drug is not suitable for all patients (Andersson 2015).

Extracellular $\mathrm{Ca}^{2+}$ influx in response to depletion of intracellular $\mathrm{Ca}^{2+}$ stores, a process termed store-operated $\mathrm{Ca}^{2+}$ entry (SOCE), is known to play an important role in a number of cell types. The ubiquitously expressed STIM proteins serve as $\mathrm{SR} \mathrm{Ca}^{2+}$ sensors and members of the Orai family (Feske et al. 2016) of transmembrane proteins as the entities responsible for mediating $\mathrm{Ca}^{2+}$ entry. In response to a decrease in $\mathrm{SR} \mathrm{Ca}^{2+}$ concentrations, STIM proteins aggregate to form discrete plasmalemmal-proximate clusters that tether and activate Orai proteins, thereby promoting extracellular $\mathrm{Ca}^{2+}$ entry. Outstanding morphological studies have shown that STIM and Orai family members are expressed in smooth muscle, and under the conditions tested, are capable of functionally coupling store depletion to extracellular $\mathrm{Ca}^{2+}$ entry (Hill-Eubanks et al. 2011).
The knowledge related to function of Orai-STIM-mediated $\mathrm{Ca}^{2+}$ entry is still limited. Orai-STIM pathway role was examined in rat model of OAB (Zhao et al. 2014), but not in human UBSM. The interpretation of data obtained in animal models may be complicated due to considerable species differences between human and animal detrusor regarding the relative contributions of $\mathrm{Ca}^{2+}$ influx (Wuest et al. 2007). Therefore, the aim of our in vitro experimental study was to specify role of Orai-STIM-mediated SOCE and other $\mathrm{Ca}^{2+}$ regulating ion channels in contraction/relaxation of human UBSM. These results may enlarge knowledge and identify possible target for future treatment of OAB symptoms in patients that are not able to tolerate or do not response to classic drugs targeting muscarinic or adrenergic receptors.

\section{Material and Methods}

\section{Tissue samples}

All processes were approved by the Institutional Ethics Committee of the Jessenius Faculty of Medicine, registered by the Institutional Review Board/Institutional Ethics Board Office (IRB 00005636), in accordance with Slovakian and European legislation (decision No. EK 1880/2016). Total 18 male patients (average age $61.5 \pm 5.9$ years) with localized prostate cancer (cT2N0M0), without OAB symptoms, were involved in current study. The following were exclusion criteria: severe systemic chronic disorders (rheumatologic, endocrine or cardiovascular), drugs influencing ion channels activity administered systemically (e.g. antiepileptics, antihypertensives or vasodilators), neurogenic bladder and/ or inflammation of lower and upper urinary tract before operation. Patient recruitment was conducted by the provision of information sheets and written informed consent was obtained. Samples $(20 \times 15 \times 10 \mathrm{~mm})$ of UBSM were obtained from macroscopic healthy tissue at ventral bladder wall immediately after open radical retropubic prostatectomy at the Urologic Clinic, Jessenius Medical Faculty and Martin University Hospital by the cold knife technique. After removing, UBSM specimen was immersed into Krebs-Henseleit's buffer of the following composition (nM): $\mathrm{NaCl}, 112.9 ; \mathrm{KCl}$, $4.7 ; \mathrm{CaCl}_{2}, 2.8 ; \mathrm{MgSO}_{4}, 0.5 ; \mathrm{NaHCO}_{3}, 24.9$; and glucose, 11.1 .

\section{Chemicals}

Oxybutynin, dimethyl sulfoxide (DMSO) and diltiazem hydrochloride were obtained from Sigma-Aldrich (Lambda life, Slovakia). 2APB, 3-fluoropyride-4-carboxylic acid and SKF96365 were purchased from Tocris Bioscience (USA) and mirabegron was purchased from Astellas Pharma Inc. (Japan). All chemicals were dissolved in aqua pro injection except from $2 \mathrm{APB}$, which was soluble in 10\% DMSO. 
Isolated bladder smooth muscle contractile response under in vitro conditions

From one tissue sample originated from particular patient were prepared 7 isolated UBSM strips. The contractility of these isolated UBSM samples was investigated by an organ tissue bath method that was well-described previously (Franova et al. 2009). Briefly, isolated UBSM strips (approximate size of each one $15 \times 5 \times 5 \mathrm{~mm}$ ) were immediately placed into tissue bath chambers filled with Krebs-Henseleit's buffer. The chambers were saturated by pneumoxide $(95 \%$ $\mathrm{O}_{2}+5 \% \mathrm{CO}_{2}$ ) at a temperature of $36 \pm 0.5^{\circ} \mathrm{C}$ and maintained at $\mathrm{pH} 7.5 \pm 0.1$. Carbachol at a concentration of $1 \mu \mathrm{M}$ was used to induce initial contractions of all strips. The involvement of individual $\mathrm{Ca}^{2+}$-regulating ion channels in the amplitude of UBSM contractions was tested using their blockers at four different concentrations $(1 \mu \mathrm{M}, 10 \mu \mathrm{M}, 100 \mu \mathrm{M}$ and $1 \mathrm{mM}$ ) in Multi-Chamber Tissue Bath Systems (Experimetria-ISO-09-TSZ8) equipped with ISO-SYS software. For comparative purposes, positive control drugs - oxybutynin and mirabegron were tested under the same conditions and at the same concentrations.

The following agents were used to influence $\mathrm{Ca}^{2+}$-regulating ion channels activity: $i$. 3-fluropyridine-4-carboxylic acid

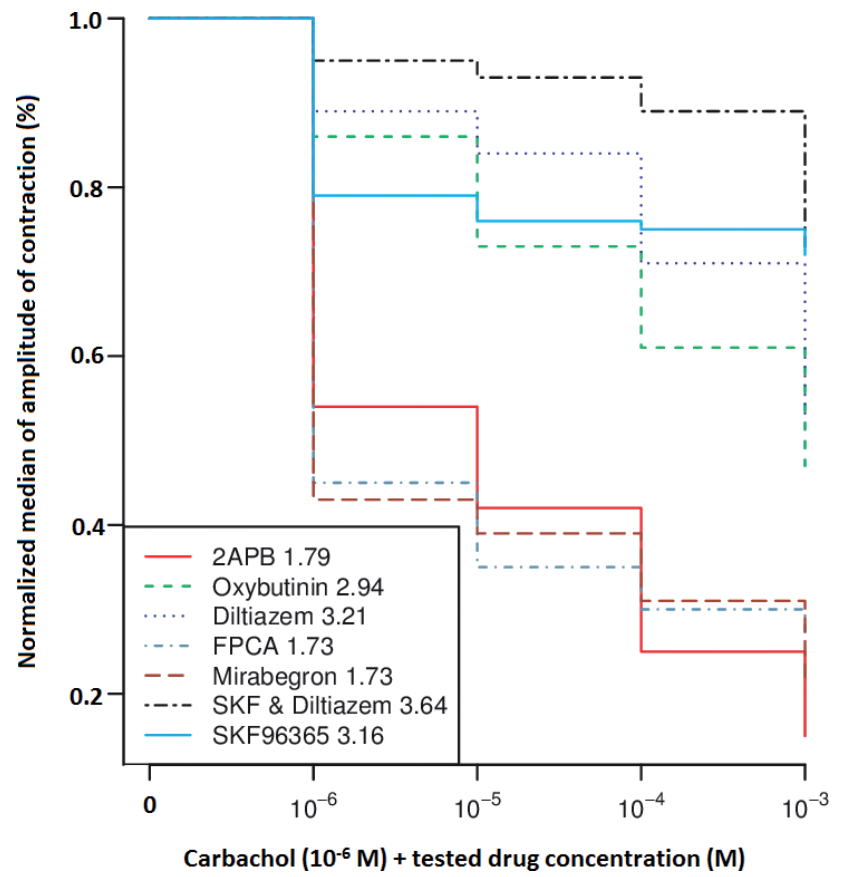

Figure 2. Normalized median of amplitude of contraction, expressed as \% of an initial tension induced by carbachol $(c=1 \mu \mathrm{M})$ measured as a response on administration of increased tested agents concentrations. The left bottom corner contains legend to figure with calculated area under the contractile curve for each followed agent.
(FPCA), blocker of Orai1-STIM1- coupling; ii. Diltiazem (DIL), L-type VGCC channel blocker; iii. SKF 96365 hydrochloride (SKF), blocker of SOCE and $\mathrm{K}^{+}$channels; $i v$. 2 - aminoethoxydiphenyl borate (2APB), $\mathrm{IP}_{3} \mathrm{Rs}$, Orai and STIM1 antagonist; $v$. Diltiazem + SKF 96365 hydrochloride (DIL+SKF).

\section{Statistical analysis}

Statistical analysis was performed in R (R Core Team 2015) using libraries WRS2 (Mair et al. 2016) and car (Fox and Weisberg 2011). Normality of the data was assessed by quantile-quantile plots with bootstrap confidence intervals. Since the normalized amplitudes of contraction were not found Gaussian, the robust ANOVA was used for evaluation. Post-hoc confidence intervals were adjusted to control the family-wise error rate. Results with $p$-value below 0.05 were considered statistically significant. For each chemical, the median normalized amplitudes of contraction was computed, and expressed as percentage of the median for carbachol. For resulting contractile curves the Area Under the Contractile Curve (AUCC) was computed by Simpson's rule using the library Bolstad2 (Curran and Bolstad 2013).

\section{Results}

The lower ability in suppression of carbachol-induced UBSM amplitude of contraction was evidenced on increasing doses

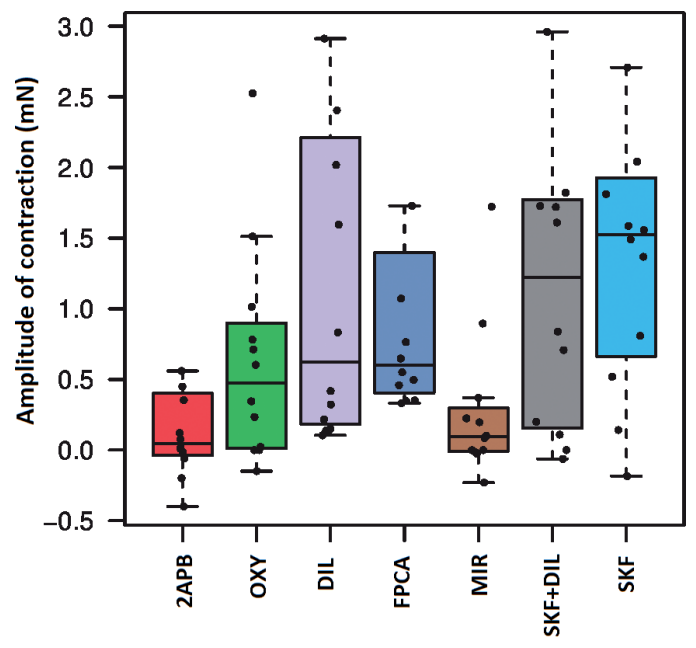

Figure 3. The boxplot of amplitude of contraction $(\mathrm{mN})$ computed for all used concentration of tested chemicals. Boxplot exhibits the first and third quartiles as the bottom and top of the box. The band inside the box is the median of a data, whiskers indicating variability outside the upper and lower quartiles. Outliers may be plotted as individual points. For abbreviations explanation, see also legend to Fig. 1. 
of SKF, DIL, SKF+DIL and also positive control drug oxybutynin. In addition, mirabegron, $2 \mathrm{APB}$ and FPCA exhibited better suppressive effect on isolated UBSM contractility induced by muscarinic receptors stimulation. As expressed by AUCC, the highest AUCC was 3.64 for DIL+SKF, followed by 3.21 for DIL, 3.16 for SKF and 2.94 for oxybutynin. The other group comprised $2 \mathrm{APB}, \mathrm{FPCA}$, mirabegron, which have similar AUCC: 1.79, 1.73, 1.73; respectively (Fig. 2).

Boxplot of the normalized amplitudes of contraction (in $\mathrm{mN}$ ) for all considered chemicals is exhibited at Fig. 3. For a chemical, the boxplot exhibits the first and third quartiles as the bottom and top of the box. The band inside the box is the median of a data. The lowest median amplitude of contraction is in 2APB followed by mirabegron and DIL; the highest median is for SKF and SKF+DIL. Whiskers are those used in the Tukey boxplot. The data points above and below the whiskers can be considered outliers. The lowest variability in the amplitude of contraction can be observed for 2APB, mirabegron and FPCA; the highest for DIL (Fig. 3).

The robust ANOVA test rejected the equality of medians hypothesis $(p=0.0017)$. $p$-value and the $95 \%$ confidence interval for post-hoc tests are in Table 1. Judging by the nonadjusted $p$-values, there were statistically significant differences in the group medians of the normalized amplitudes of contraction between: $2 \mathrm{APB}$ and DIL; 2APB and DIL+SKF; 2APB and SKF; DIL and FPCA; FPCA and DIL+SKF; FPCA and SKF.

The FEW-adjusted $95 \%$ confidence interval permits making additional conclusions. The median normalized amplitude of contraction in $2 \mathrm{APB}$ is significantly lower than the median normalized amplitude of contraction of SKF. Similarly, the median normalized amplitude of contraction in FPCA is significantly lower than the median normalized amplitude of contraction of SKF (Table 1).

\section{Discussion}

In this study our attention was concerned on the $\mathrm{Ca}^{2+}$ ion channels that are believed as the most important in contractile activity of UBSM: VGCC (L-type and T-type), $\mathrm{IP}_{3}$ Rs and SOCE (TRPC superfamily and Orai-STIM channels). The in-

Table 1. $p$-value (calculated using robust ANOVA) and the $95 \%$ confidence interval (CI) for post-hoc test evaluated by comparison of individual compounds

\begin{tabular}{|c|c|c|c|c|c|c|c|c|c|c|c|c|}
\hline \multirow{3}{*}{$\begin{array}{l}\text { Comparison } \\
\text { of compounds }\end{array}$} & \multicolumn{12}{|c|}{ Concentration of compounds } \\
\hline & \multicolumn{3}{|c|}{$1 \mathrm{mM}$} & \multicolumn{3}{|c|}{$100 \mu \mathrm{M}$} & \multicolumn{3}{|c|}{$10 \mu \mathrm{M}$} & \multicolumn{3}{|c|}{$1 \mu \mathrm{M}$} \\
\hline & lower CI & upper CI & $p$ & lower $\mathrm{CI}$ & upper CI & $p$ & lower $\mathrm{CI}$ & upper CI & $p$ & lower $\mathrm{CI}$ & upper CI & $p$ \\
\hline 2APB vs. OXY & -2.73 & 0.98 & 0.09 & -2.68 & 0.86 & 0.07 & -2.68 & 0.82 & 0.06 & -2.66 & 0.72 & $0.05^{*}$ \\
\hline $2 \mathrm{APB} v s . \mathrm{DIL}$ & -1.70 & 0.42 & $0.04^{*}$ & -1.68 & 0.31 & $0.02^{*}$ & -1.68 & 0.18 & $0.01^{*}$ & -1.77 & 0.07 & $0.005^{*}$ \\
\hline 2APB vs. FPCA & -0.44 & 0.43 & 0.99 & -0.70 & 0.57 & 0.71 & -0.77 & 0.63 & 0.73 & -0.85 & 0.73 & 0.78 \\
\hline 2APB vs. MIR & -1.15 & 0.46 & 0.13 & -1.20 & 0.35 & 0.06 & -1.31 & 0.31 & $0.04^{*}$ & -1.41 & 0.26 & $0.02^{*}$ \\
\hline $2 \mathrm{APB} v s . \mathrm{SKF}+\mathrm{DIL}$ & -2.42 & 0.47 & $0.02^{*}$ & -2.72 & 0.48 & $0.02^{*}$ & -2.81 & 0.33 & $0.01^{*}$ & -2.96 & 0.40 & $0.01^{*}$ \\
\hline $2 \mathrm{APB} v s . \mathrm{SKF}$ & -2.42 & -0.13 & $0.002^{*}$ & -3.21 & -0.22 & $0.008^{\star}$ & -3.49 & 0.33 & $0.01^{*}$ & -3.66 & 0.38 & $0.01^{\star}$ \\
\hline OXY vs. DIL & -1.67 & 2.14 & 0.65 & -1.59 & 2.04 & 0.65 & -1.60 & 1.96 & 0.71 & -1.60 & 1.84 & 0.80 \\
\hline OXY vs. FPCA & -0.97 & 2.74 & 0.09 & -0.93 & 2.61 & 0.09 & & 2.62 & 0.08 & -0.79 & 2.61 & 0.06 \\
\hline OXY vs. MIR & -1.33 & 2.39 & 0.29 & -1.30 & 2.26 & 0.32 & -1.33 & 2.19 & 0.37 & -1.30 & 2.11 & 0.39 \\
\hline OXY vs. SKF+DIL & -2.18 & 1.92 & 0.86 & -2.68 & 1.51 & 0.33 & -2.31 & 1.94 & 0.59 & -2.33 & 1.71 & 0.59 \\
\hline OXY vs. SKF & -2.32 & 1.52 & 0.45 & -0.41 & 1.64 & $0.04^{*}$ & -2.85 & 1.55 & 0.31 & -2.92 & 1.58 & 0.30 \\
\hline DIL vs. FPCA & -0.42 & 1.70 & $0.04^{*}$ & -0.82 & 1.33 & 0.40 & -0.30 & 1.67 & $0.03^{*}$ & 0.24 & 1.83 & $0.01^{\star}$ \\
\hline DIL vs. MIR & -0.85 & 1.44 & 0.36 & -2.68 & 0.86 & 0.07 & -0.79 & 1.29 & 0.40 & -0.77 & 1.34 & 0.35 \\
\hline DIL vs. SKF+DIL & -1.88 & 1.21 & 0.45 & -1.68 & 0.31 & $0.02^{\star}$ & -2.10 & 1.12 & 0.28 & -2.14 & 1.29 & 0.37 \\
\hline DIL vs. SKF & -1.97 & 0.69 & 0.11 & -2.09 & 1.22 & 0.35 & -2.76 & 1.10 & 0.13 & -2.82 & 1.24 & 0.16 \\
\hline FPCA $v s$. MIR & -1.14 & 0.45 & 0.12 & -2.57 & 0.95 & 0.11 & -1.32 & 0.46 & 0.11 & -1.48 & 0.46 & 0.08 \\
\hline FPCA $v s$. SKF+DIL & -2.42 & 0.47 & $0.02^{\star}$ & -2.66 & 0.54 & $0.03^{\star}$ & -2.75 & 0.41 & $0.02^{\star}$ & -2.91 & 0.47 & $0.02^{*}$ \\
\hline FPCA $v s$. SKF & -2.42 & -0.13 & $0.002^{*}$ & -3.15 & 0.29 & $0.009^{*}$ & -3.42 & 0.40 & $0.01^{*}$ & -3.61 & 0.44 & $0.01^{\star}$ \\
\hline MIR vs. SKF+DIL & -2.10 & 0.85 & 0.14 & -2.31 & 0.92 & 0.13 & -2.33 & 0.85 & 0.11 & -2.41 & 0.99 & 0.14 \\
\hline MIR vs. SKF & -2.15 & 0.28 & $0.01^{*}$ & -2.79 & 0.66 & $0.04^{\star}$ & -2.99 & 0.83 & $0.05^{\star}$ & -3.09 & 0.95 & 0.07 \\
\hline SKF+DIL $v s$. SKF & -1.89 & 1.28 & 0.5 & -2.37 & 1.6 & 0.51 & -2.45 & 1.77 & 0.57 & -2.61 & 1.88 & 0.57 \\
\hline
\end{tabular}

Statistically significant data are marked by *. 2APB, 2-aminoethoxydiphenyl borate; OXY, oxybutynin; DIL, diltiazem; FPCA, 3-fluropyridine-4-carboxylic acid; MIR, mirabegron; SKF, SKF 96365-hydrochloride. 
dividual ion channels activity was modulated by DIL, FPCA, SKF and 2APB and organ tissue bath method was selected for evaluation. UBSM strips have been employed over the years by many groups to answer a number of scientific questions, including examination of the effects of drugs that modulate smooth muscle tone with the aim of discovering ion channels and/or receptors and/or intracellular pathways that could be targeted to induce either relaxation or contraction (Kullmann et al. 2014). This relatively simple in vitro method was used to discover and test compounds currently used for OAB management (Svalø et al. 2013). As it is distinct from clinical trials, $\mathrm{M}_{3}$ antimuscarinics and agonists of $\beta_{3}$-ARs possess relatively reliable effect; however, such treatment has several significant limitation; e.g. antimuscarinic side effects or cardiotoxicity and CNS toxicity resulting from adrenergic stimulation. Oxybutynin and mirabegron were selected as positive control drugs in this study. We confirmed that antimuscarinic drug oxybutynin and $\beta_{3} \mathrm{AR}$ agonist mirabegron effectively and dose-dependently decreased amplitude of carbachol-induced contraction in isolated UBSM. Our results did not evidence any significant differences in the effectiveness between both agents. According to molecular mechanisms involved in oxybutynin and mirabegron mechanism of action, it is distinct that UBSM contractile activity is significantly regulated especially by $\mathrm{Ca}^{2+}$ and $\mathrm{K}^{+}$ion channels.

DIL is a non-dihydropyridine L-type VGCC blocker used in the treatment of hypertension, angina pectoris, and some types of cardiac arrhythmia. FPCA dose-dependently inhibits Orail-STIM1 coupling (Whitten et al. 2011). SKF is an imidazole compound 1-[ $\beta$ - [3-(4-methoxyphenyl) propoxy]-4-methoxyphenethyl] -1H-imidazole hydrochloride. SKF effect rests with used concentration: at $\mathrm{c}=1-10 \mu \mathrm{M}$ this agent inhibits T-type VGCC, from $\mathrm{c}=10 \mu \mathrm{M}$ blocks also TRPC (Singh et al. 2010), $\mathrm{K}^{+}$ATP and $\mathrm{BK}^{+} \mathrm{Ca}$ channels; and prevents Orail-STIM1 coupling in dose-dependent manner (Tanahashi et al. 2016). 2APB was originally described as an $\mathrm{IP}_{3}$ Rs antagonist and was later shown to inhibit SOCE and $I_{\text {CRAC }}$ dose-dependently, independently of $\mathrm{IP}_{3}$ Rs inhibition. $2 \mathrm{APB}$ effect is related to concentration. $2 \mathrm{APB}$ at low concentrations $(c=1 \mu \mathrm{M}$ and $10 \mu \mathrm{M})$ inhibits $\mathrm{IP}_{3}$ Rs, while it's higher concentrations ( $c=100 \mu \mathrm{M}$ and $1 \mathrm{mM}$ ) are able to block Orai and STIM1 structure (Orai1 $>>$ STIM1 $>>$ Orai2, Orai3) (DeHaven et al. 2008).

The lower $(1 \mu \mathrm{M}$ and $10 \mu \mathrm{M})$ and higher $(100 \mu \mathrm{M}$ and $1 \mathrm{mM}$ ) used concentrations of tested agents allowed to mutually compare the involvement of the different $\mathrm{Ca}^{2+}$ sources in human isolated carbachol-induced UBSM contraction (for further explanation see Fig. 1).

At lower used concentrations of tested modulators, the results confirmed the most significant relaxing effect of 2APB, FPCA and mirabegron. This indicated essential role of $\mathrm{Ca}^{2+}$ released from internal sources upon $\mathrm{IP}_{3}$ Rs activation and $\mathrm{Ca}^{2+}$-induced $\mathrm{Ca}^{2+}$ release in human UBSM contrac- tion. The release of $\mathrm{Ca}^{2+}$-mediated by $\mathrm{IP}_{3}$ Rs activation is generally accepted as a principal mechanism in $\mathrm{M}_{3}$ receptors mediated detrusor activity. Furthermore, it was showed that $2 \mathrm{APB}$ possessed significantly better suppressive effect than antimuscarinic drug oxybutynin, despite that both in essence inhibited the same target - release of $\mathrm{Ca}^{2+}$ through $\mathrm{IP}_{3}$ Rs. As it was recently reported that muscarinic receptor induced contractions of the detrusor (and also effect of oxybutynin) is mediated not only by $\mathrm{IP}_{3} \mathrm{Rs}$ but partially also by TRPC4 $\beta$ channels (Griffin et al. 2016). The suppression of carbachol-induced UBSM contraction similar to 2APB was observed on mirabegron. Cernecka et al. (2015) reported similar data and confirmed a significant contribution of $\mathrm{BK}^{+} \mathrm{Ca}$ channels in $\beta_{3} \mathrm{AR}$-mediated human UBSM relaxation after precontraction with carbachol. Thus, in human UBSM cells $\mathrm{BK}^{+} \mathrm{Ca}$ channel outward currents have been shown to be a major determinant of repolarization following action potentials (Bentzen et al. 2014). The lower importance of $\mathrm{Ca}^{2+}$ transported though TRPC and VGCC (both T-type and L-type) than release of $\mathrm{Ca}^{2+}$ from ER in carbachol-induced contraction of isolated human UBSM was clear from significant differences between SKF and 2APB, DIL and 2APB or SKF+DIL and $2 \mathrm{APB}$ effects. This corresponded with Wuest et al. (2007) revealed that block of L-type VGCC with nifedipine impaired carbachol-induced contractions markedly less in human than in animal detrusor. Howbeit the role of ER $\mathrm{Ca}^{2+}$ stores and SOCE in various smooth muscle types was noticeably studied within previous two decades suggested significant involvement of Orai-STIM pathway and TRPC in control of smooth muscle contractile activity (Wang et al. 2008); only Zhao et al. (2014) experimental study in rats confirmed the role of SOCE in UBSM. Our study, for the first time, pointed on this mechanism as an important regulator of UBSM contractility. At higher used concentrations of tested agents, FPCA relaxing effect was comparable to $2 \mathrm{APB}$ and mirabegron and both Orai-STIM pathway inhibitors possessed significantly higher suppressive activity than SKF. As it was reported only recently, SKF in such concentrations inhibited not only Orai-STIM coupling but also $\mathrm{BK}^{+} \mathrm{Ca}$ and $\mathrm{K}^{+}$ATP channels (Tanahashi et al. 2016).

Several studies investigated UBSM contractility confirmed changes in contractile response of subjects with bladder outflow obstruction and in effect of UBSM relaxing drugs (Svalø et al. 2013; Zhao et al. 2014) and proposed alteration in ion channels expression/activity as the main reason of this finding. Aydin et al. (2012) demonstrated an approximate 5-fold decrease in bladder myocytes $\mathrm{BK}^{+} \mathrm{Ca}$ activity that may enhance basal and nerve-mediated UBSM contractility, leading to bladder overactivity and urinary incontinence (Meredith et al. 2004). In addition, $\mathrm{Ca}^{2+}$ ions that activate $\mathrm{BK}^{+} \mathrm{Ca}$ channels are released from RyRs, which expression decreased in detrusor instability (Jiang et al. 2005). The balance between T-type and L-type $\mathrm{Ca}^{2+}$ 
currents is altered in myocytes from overactive human bladders, with the T-type component proportionately increased and slightly significantly decreased L-type current (Sui et al. 2007). This contributed on increased incidence of intracellular $\mathrm{Ca}^{2+}$ transients and spontaneous action potentials in cells from OAB. Zhao et al. (2014) revealed significant variations in muscle contraction when compared effect of SOCE activator and inhibitor (SKF 96365) in healthy rats and the animals with experimentally-induced detrusor overactivity, suggested changes in expression of Orai-STIM pathway components. All pathological changes in $\mathrm{OAB}$ related to ion channels activity/expression can possibly alter the response on classic treatment. We consider that targeting of Orai or STIM by tissue-selective inhibitors would produce detrusorspecific effects on $\mathrm{Ca}^{2+}$ dynamics. Nevertheless, there is still much to be learned about the interactions among and influence of the many components that regulate intracellular $\mathrm{Ca}^{2+}$ in UBSM and further research in this area is warranted.

In conclusion, the present results confirmed, for the first time, that SOCE involving Orai-STIM pathway plays an important role in human isolated UBSM contractile activity. Inhibition of Orai-STIM channels would prevent $\mathrm{Ca}^{2+}$ overload state that would lead to overstimulation of RyRs and $\mathrm{IP}_{3} \mathrm{Rs}$ from their luminal sides and thus the enhanced spontaneous activity, as it has been reported for cardiac muscle (Stultzmann and Mattson 2011). In this study the inhibition of Orai-STIM pathway produced suppressive effect on USBM carbachol-induced contraction similar to effect seen on inhibition of $\mathrm{IP}_{3}$ Rs by $2 \mathrm{APB}$ or activation of $\beta_{3}-\mathrm{cAMP}-\mathrm{BK}^{+} \mathrm{Ca}$ pathway by mirabegron. Orai-STIM channels may represent novel therapeutic targets for $\mathrm{OAB}$ pharmacotherapy. Future studies focused on their role in patients with $\mathrm{OAB}$ are warranted. The potential clinical application of Orai-STIM modulation for OAB therapy should be further validated in clinical trials.

Acknowledgement. The authors acknowledge Katarina Jesenska for her outstanding technical assistance during experimental works. This study was supported by the project "BioMed" ITMS 26220220187 co-financed from EC sources, grants UK/57/2017 and VEGA No. 1/0062/11, 1/0127/13 and 1/0163/16.

Conflict of interest. The authors declare that the research was conducted in the absence of any commercial or financial relationships that could be construed as a potential conflict of interest.

\section{References}

Afeli SAY, Rovner ES, Petkov GV (2013): BRL37344, a $\beta 3$ adrenergic receptor agonist, decreases nerve-evoked contractions in human detrusor smooth muscle isolated strips: role of BK channels. Urology 82, e1-e7

https://doi.org/10.1016/j.urology.2013.05.027
Andersson KE (2015): Drug therapy of overactive bladder - What is comming next? Korean J. Urol. 56, 673-679 https://doi.org/10.4111/kju.2015.56.10.673

Aydin M, Wang HZ, Zhang X, Chua R, Downing K, Melman A, DiSanto ME (2012): Large-conductance calcium-activated potassium channel activity, as determined by whole-cell patch clamp recording, is decreased in urinary bladder smooth muscle cells from male rats with partial urethral obstruction. BJU International. 110, E402-E408 https://doi.org/10.1111/j.1464-410X.2012.11137.x

Bentzen BH, Olesen S-P, Rønn LCB, Grunnet M (2014): BK channel activators and their therapeutic perspectives. Front. Physiol. 5, 389 https://doi.org/10.3389/fphys.2014.00389

Cernecka H, Kersten K, Maarsingh H, Elzinga CR, de Jong IJ, Korstanje C, Michel MC, Schmidt M (2015): $\beta 3$-Adrenoceptormediated relaxation of rat and human urinary bladder: roles of BKCa channels and Rho kinase. Naunyn Schmiedebergs Arch. Pharmacol. 388, 749-759 https://doi.org/10.1007/s00210-015-1128-z

Curran J, Bolstad W (2013): Bolstad: Bolstad functions. R package version 1.0-28, https://CRAN.R-project.org/package $=$ Bolstad2

DeHaven WI, Smyth JT, Boyles RR, Bird GS, Putney JW Jr (2008): Complex actions of 2-aminoethyldiphenyl borate on storeoperated calcium entry. J. Biol. Chem. 283, 19265 https://doi.org/10.1074/jbc.M801535200

Feske S, Gwack Y, Prakriya M, Srikanth S, Puppel SH, Tanasa B, Hogan PG, Lewis RS, Daly M, Rao A (2016): A mutation in Orail causes immune deficiency by abrogating CRAC channel function. Nature 441, 179-185 https://doi.org/10.1038/nature04702

Franova S, Janicek F, Visnovsky J, Dokus K, Zubor P, Sutovska M, Nosalova G (2009): Utero-relaxant effect of PDE4-selective inhibitor alone and in simultaneous administration with $\beta 2$-mimetic on oxytocin-induced contractions in pregnant myometrium. J. Obstet. Gynaecol. Res. 35, 20-25 https://doi.org/10.1111/j.1447-0756.2008.00839.x

Fox J, Weisberg S (2011): An R Companion to Applied Regression. Second Edition. Thousand Oaks CA, Sage

Griffin CS, Bradley E, Dudem S, Hollywood MA, McHale NG, Thornbury KD, Sergeant GP (2016): Muscarinic receptor induced contractions of the detrusor are mediated by activation of TRPC4 channels. J. Urol. 196, 1796-1808 https://doi.org/10.1016/j.juro.2016.05.108

Hedge SS (2006): Muscarinic receptors in the bladder: from basic research to therapeutics. Br. J. Pharmacol. 147, S80-S87 https://doi.org/10.1038/sj.bjp.0706560

Herrera GM, Nelson MT (2002): Differential regulation of SK and BK channels by $\mathrm{Ca}(2+)$ signals from $\mathrm{Ca}(2+)$ channels and ryanodine receptors in guinea-pig urinary bladder myocytes. J. Physiol. 541, 483-492 https://doi.org/10.1113/jphysiol.2002.017707

Hill-Eubanks DC, Werner ME, Heppner TJ, Nelson MT (2011): Calcium signaling in smooth muscle. Cold Spring Harb. Perspect. Biol. 3, a004549 https://doi.org/10.1101/cshperspect.a004549

Hristov KL, Cui X, Brown SM, Liu L, Kellett WF, Petkov GV (2008): Stimulation of $\beta 3$-adrenoceptors relaxes rat urinary 
bladder smooth muscle via activation of the large-conductance Ca2+-activated K+ channels. Am. J. Physiol. Cell Physiol. 295, C1344-C1353 https://doi.org/10.1152/ajpcell.00001.2008

Jiang HH, Song B, Lu GS, Wen QJ, Jin XY (2005): Loss of ryanodine receptor calcium-release channel expression associated with overactive urinary bladder smooth muscle contractions in a detrusor instability model. BJU International. 96, 428-433 https://doi.org/10.1111/j.1464-410X.2005.05644.x

Khullar V, Amarenco G, Angulo JC, Cambronero J, Hoye K, Milson I, Radziszewski P, Rechberger T, Boerrigter P, Drogendijk T, et al. (2013): Efficacy and tolerability of mirabegrone, a $\beta 3$ adrenoreceptor agonist, in patients with overactive bladder: results from a randomised european-australian phase 3 Trial. Eur. Urol. 63, 283-295 https://doi.org/10.1016/j.eururo.2012.10.016

Kullmann FA, Daugherty SL, de Groat WC, Birder LA (2014): Bladder smooth muscle strip contractility as a method to evaluate lower urinary tract pharmacology. J. Vis. Exp. 90, e51807 https://doi.org/10.3791/51807

Mair P, Schoenbrodt F, Wilcox R (2016): WRS2: Wilcox robust estimation and testing ( $\mathrm{R}$ package Version 0.9.1) [Software package] https://cran.r-project.org/web/packages/ WRS2/

Meredith AL, Thorneloe KS, Werner ME, Nelson MT, Aldrich RW (2004): Overactive bladder and incontinence in the absence of the BK large conductance Ca2+-activated K+ channel. J. Biol. Chem. 279, 36746-36752 https://doi.org/10.1074/jbc.M405621200

Parajuli SP, Zheng Y-M, Levin R, Wang Y-X (2016): Big-conductance $\mathrm{Ca} 2+$-activated $\mathrm{K}+$ channels in physiological and pathophysiological urinary bladder smooth muscle cells. Channels 10, 355-364 https://doi.org/10.1080/19336950.2016.1180488

R Core Team (2015): R: A language and environment for statistical computing. R Foundation for Statistical Computing, Vienna, Austria

Singh A, Hildebrand M, Garcia E, Snutch T (2010): The transient receptor potential channel antagonist SKF96365 is a potent blocker of low-voltage-activated T-type calcium channels. Br. J. Pharmacol. 160, 1464-1475 https://doi.org/10.1111/j.1476-5381.2010.00786.x
Svalø J, Nordling J, Bouchelouche K, Andersson KE, Korstanje C, Bouchelouche P (2013): The novel $\beta 3$-adrenoceptor agonist mirabegron reduces carbachol-induced contractile activity in detrusor tissue from patients with bladder outflow obstruction with or without detrusor overactivity. Eur. J. Pharmacol. 699, 101-105

https://doi.org/10.1016/j.ejphar.2012.11.060

Stutzmann GE, Mattson MP (2011): Endoplasmic reticulum Ca2+ handling in excitable cells in health and disease. Pharmacol. Rev. 63, 700-727

https://doi.org/10.1124/pr.110.003814

Sui GP, Wu C, Severs N, Newgreen D, Fry CH (2007): The association between T-type Ca2+ current and outward current in isolated human detrusor cells from stable and overactive bladders. BJU International. 99, 436-441 https://doi.org/10.1111/j.1464-410X.2006.06568.x

Tanahashi Y, Wang B, Murakami Y, Unno T, Matsuyama H, Nagano H, Komori S (2016): Inhibitory effects of SKF96365 on the activities of $\mathrm{K}+$ channels in mouse small intestinal smooth muscle cells. J. Vet. Med. Sci. 78, 203-211 https://doi.org/10.1292/jvms.15-0346

Wang Y, Deng X, Hewavitharana T, Soboloff J, Gill DL (2008): STIM, Orai and TRPC channels in the control of calcium entry signals in smooth muscle. Clin. Exp. Pharm. Physiol. 35, 1127-1133 https://doi.org/10.1111/j.1440-1681.2008.05018.x

Whitten JP, Pei J, Cao J, Wang Z, Rogers E, Dyck B, Grey J (2011): Compounds that modulate intracellular calcium. US patent No. WO/2011/139765

Wuest M, Hiller N, Braeter M, Hakenberg OW, Wirth MP, Ravens U (2007): Contribution of Ca2+ influx to carbachol-induced detrusor contraction is different in human urinary bladder compared to pig and mouse. Eur. J. Pharmacol. 565, 180-189 https://doi.org/10.1016/j.ejphar.2007.02.046

Zhao B, Zhong X, Bai X, Wang Q, Song B, Li L (2014): Changes in store-operated calcium channels in rat bladders with detrusor overactivity. Urology 84, 491.e1-6 https://doi.org/10.1016/j.urology.2014.05.007

Received: October 10, 2017

Final version accepted: December 4, 2017

First published online: June 29, 2018 